\title{
STASIUN KERETA API DENGAN KONSEP UTOPIA DI KOTA MAKASSAR
}

\author{
${ }^{1}$ Melita Thila, ${ }^{2}$ Noviar Nurdin Kasim, ${ }^{3}$ Meldawati Artayani \\ ${ }^{1}$ Mahasiswa Teknik Arsitektur, F.Teknik, UNIFA, Makassar, e-mail: melitathila@gmail.com \\ ${ }^{2.3 .}$ Dosen Teknik Arsitektur,F.Teknik, UNIFA, Makassar
}

\begin{abstract}
ABSTRAK
Kota Makassar sebagai,pintu gerbang perdagangan di Indonesia Timur dan juga merupakan salah satu kota besar di Indonesia, membutuhkan moda transportasi massal yakni kereta api yang telah ditindaklanjuti dengan adanya jaringan jalur kereta api Trans Sulawesi pada tahun 2015 di Kabupaten Barru. Sejauh ini perencanaan kereta api hanya sebatas rencana jaringan jalur kereta tanpa adanya rencana rancangan stasiun. Oleh karena itu dibutuhkan sebuah desain Stasiun Kereta Api di Kota Makassar sebagai induk dari stasiun-stasiun penghubung antarkota lainnya. Penggunaan metode pendekatan utopia menekankan bentuk fasade yang geometris dan dinamis yang ditransformasikan dari bentuk lumba-lumba untuk menghadirkan kesan futuristik pada bangunan yang berlokasi pada Kecamatan Tallo tersebut. Dengan luas lahan terbangun 2,7 Ha dan lahan terbuka 1,8 Ha, Stasiun didesain tiga lantai dengan sistem struktur rangka ruang dipadukan GFRC (Glass Fiber Reinforced Concrete). Pada tapak terdapat pembagian jalur enterance antara penumpang, pengelola dan barang atau kargo. Fasilitas yang disediakan pada tapak adalah halte angkutan umum yakni BRT dan pete-pete guna memperlancar perpindahan moda transportasi penumpang. Stasiun Kereta Api dengan konsep utopia ini penulis sajikan agar dapat menjadi ikon Kota Makassar, sesuai dengan program kerja pemerintah yakni menjadikan Kota Makassar sebagai kota dunia. Selain itu juga dapat memperpanjang masa pakai bangunan dari segi arsitektural sehingga bangunan tidak perlu direnovasi dalam kurun waktu yang singkat.
\end{abstract}

Kata Kunci :Stasiun Kereta Api, Utopia, Kota Makassar

\section{PENDAHULUAN}

Angkutan mobilisasi antar kota di Pulau Sulawesi yang tersedia diantaranya bus-bus antarkota dan mobilmobil sewa sebagai penghubung jalur darat antar kota di Pulau Sulawesi. Tentu saja transportasi tersebut terbatas dari segi kapasitas muatan angkutan. Hal ini menyebabkan banyaknya moda transportasi yang beroperasi sehingga menyebabkan terbatasnya ruang gerak antar kota bahkan mengakibatkan macetnya lalulintas pada waktu-waktu tertentu seperti pada masa liburan semester anak sekolah. Selain itu, hal tersebut juga menambah nilai pemborosan penggunaan bahan bakar dan menyebabkan kerugian materil atau pemborosan cost (biaya).

Kota Makassar sebagai IbukotaProvinsi Sulawesi Selatan, pintu gerbang perdagangan di Indonesia Timur dan juga merupakan salah satu kotabesar di Indonesia, perlu menindaklanjuti fenomena tersebut bahwa Kota Makassar sebagai jalur induk yang menghubungkan kota-kota di Pulau Sulawesi, membutuhkan moda transportasi missal yakni kereta api. Wacana ini tampaknya telah ditindaklanjuti oleh pemerintah kota dengan telah tersedianya jalur keretaapi Trans Sulawesi pada tahun 2015 di Kabupaten Barru yang dapatdilihat pada gambar 1. Dengan adanya rel kereta api, tentu saja dibutuhkan tempat yang aman dan nyaman untuk menaikkan dan menurunkan penumpang maupun barang yang kita sebut dengan Stasiun Kereta Api.
Sedangkan sejauh ini perencanaan kereta api hanya sebatas rencana jaringan jalur kereta tanpa adanya rencana rancangan stasiun.

Oleh karena itu dibutuhkan sebuah desain Stasiun Kereta Api di Kota Makassar sebagai induk dari stasiun-stasiun penghubung antar kota lainnya. Stasiun merupakan salah satu sarana umum di sebuah kota besar. Tidak jarang kita menemukan bangunan fasilitas umum yang 'biasa-biasa saja' dari segi arsitektur atau bahkan yang terlihat sebagai bangunan tua sehingga tidak butuh waktu lama untuk sebuah bangunan direnovasi. Hal ini tentu saja harus menjadi pertimbangan bagi seorang perancang untuk lebih selektif dalam memilih konsep perancangan. Di sisi lain, munculnya kebijakan masyarakat ekonomi ASEAN (MEA) di tahun 2016 ikut turut sumbangsi dalam mengharuskan seorang perancang bangunan menjadi lebih kompetitif dan berorientasi pada masa depan melalui konsep perancangannya.

Maka dari itu konsep yang tepat adalah konsep utopia yang merupakan era futuristik dan bukanlah suatu gaya tetapi suatu pendekatan terbuka kearsitektur yang mengandung nilai dinamis dengan mengadopsi bentuk bebas. Oleh karenaitu, karya ilmiah ini hadir untuk menjawab kebutuhan tersebut akan rancangan sebuah bangunan Stasiun KeretaApi di Kota Makassar dengan penekanan pada konsep 
utopia sebagai ekspresi bentuk bangunan yang berorientasi pada masa depan.

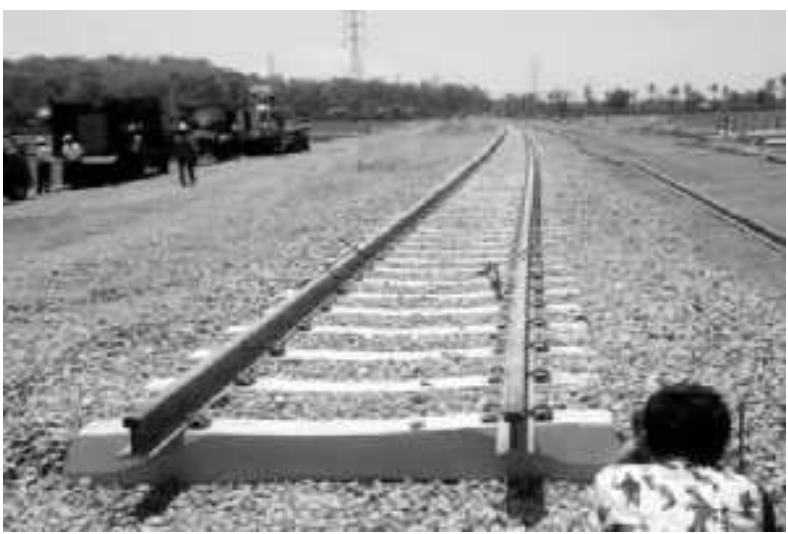

Gambar 1. Rel KeretaApi di KabupatenBarru

\section{METODE PENELITIAN}

\section{a. Waktu dan Tempat Penelitian}

Waktu penelitian dilaksanakan pada bulan Maret sampai dengan Juni 2017. Tempat penelitian dan pengolahan hasil survei di Studio Sarjana Arsitektur Universitas Fajar. Lokasi Sampling Stasiun Kereta Api di Kecamatan Tallo Kota Makassar, Sulawesi Selatan.

\section{b. Data Penunjang Terkait}

- Survey lokasi: untuk mengetahui kondisi lingkungan serta mendapatkan foto-foto tapak.

- Studi literatur: mencari data mengenai jalur kereta api dan titik lokasi penempatan stasiun dari perpustakaan digital maupun perpustakaan nondigital.

- Studi banding : mencari data stasiun kereta api di Indonesia maupun diluar negeri sebagai bahan perbandingan.

- Data yang digunakan berasal dari data Kementerian PerhubunganDirektoratJenderalPerkeretaapian yang diolah dan menghasilkan data analisis penulis.

\section{c. Metode Deskriptif}

Metode deskriptif/survey yang memberikan gambaran tentang rancangan nyata yang diteliti yang hanya fokus pada peristiwa kontemporer melalui studi literatur yang dijadikan petunjuk standar perancangan, petunjuk standar perancangan yang kemudian dianalisis dan disesuaikan dengan rancangan.

Utopia adalah bagian dari era futuristik yang melalui konsep ini diterapkan suatu angan-angan desain terbesar dari perancang melalui karakternya yang cenderung menerapkan sifat fluiditas, geometris dan bentuk bangunan yang ekspresif.

\section{d. Metode Pendekatan Arsitektural}

Arsitektur utopia akan tercipta apabila dalam proses berarsitektur menggunakan pendekatan desain yang utopis (desain futuristik). Proses pendekatan desain arsitektur yang menggabungkan dinamis, geometri, dan fluiditas menggunakan garis sebagai basis design untuk menghasilkan suatu bentuk bangunan, lansekap, permukiman dan kota.

\section{e. Kerangka Berpikir Rancangan}

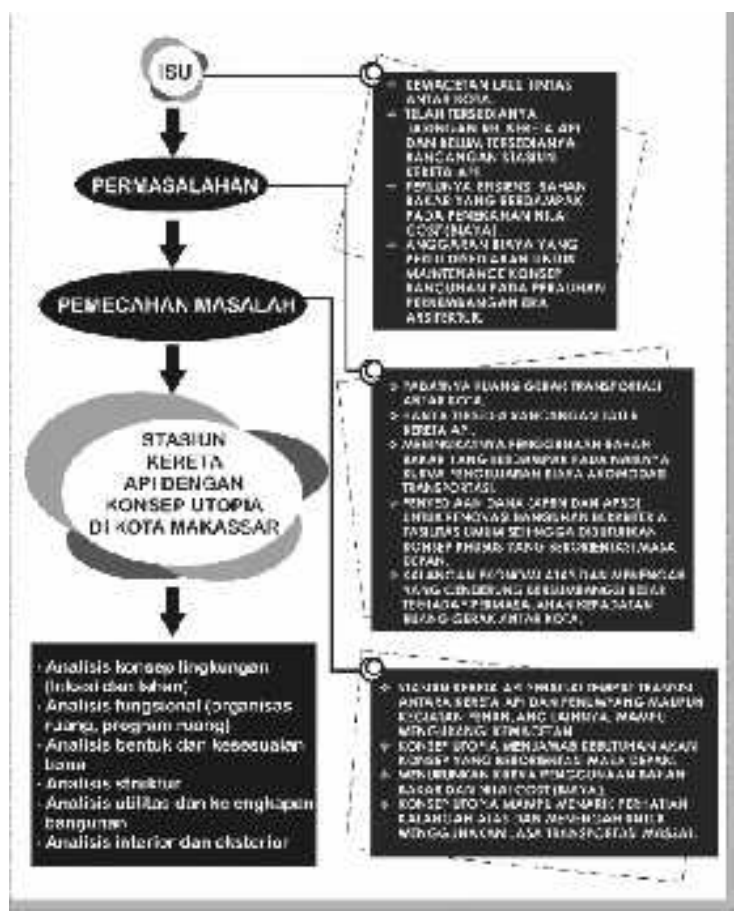

Gambar 2. Kerangka Berpikir

\section{HASIL DAN PEMBAHASAN}

a. Lokasi Perancangan

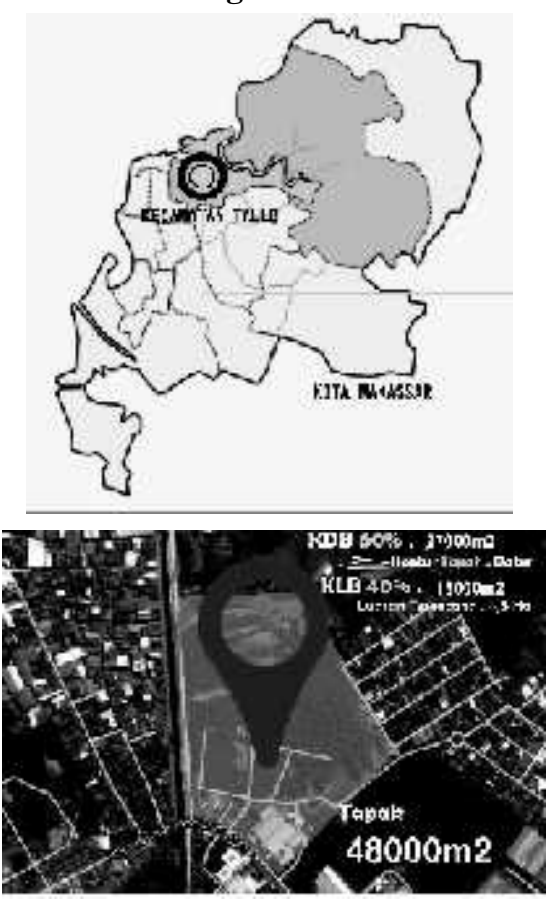

Gambar 3. Lokasi Perencanaan Stasiun Kereta Api

Lokasi perancangan berada pada kecamatan Tallo, sekawasan dengan Makassar New Port. Lahan seluas $4,8 \mathrm{Ha}$ dengan building covarage 60:40. Luasan lahan yang terpakai adalah 4,5 Ha 
dengan 0,3 Ha sebagai perluasan horisontal bangunan.

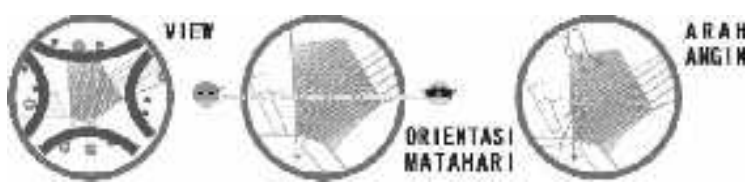

Gambar 4. Site Terencana

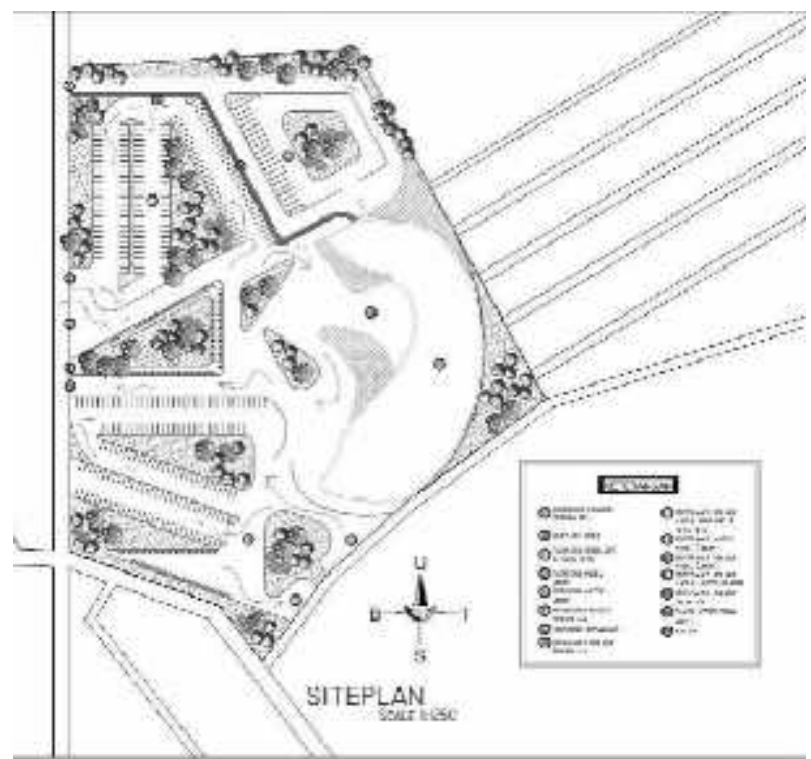

Gambar 5. Sirkulasi Tapak

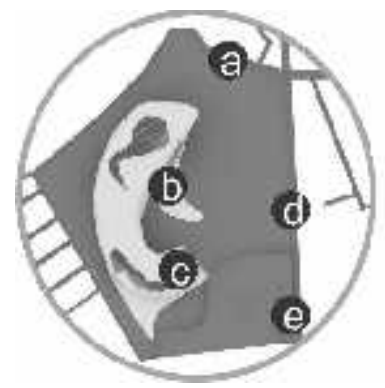

(อ) ensterize perigelulus

(9) cricrenzo porygelolasVIF

cen:eransa umuim haาgunan

(6) encerances urnum sapak

(6) en:erenze truk,pats-pete Jan BRT

Gambar 6. Sirkulasi Enterance

\section{b. Program Ruang}

Tabel.1. Kebutuhan Ruang

\begin{tabular}{|c|c|c|}
\hline No & Unit Ruang & KebutuhanRuang \\
\hline 1 & $\begin{array}{l}\text { Unit Pengelola; } \\
\text { Pimpinan Stasiun }\end{array}$ & $\begin{array}{l}\text { Rg. KepalaStasiun, Rg. } \\
\text { Wakil KepalaStasiun, } \\
\text { Rg. Sekertaris, } \\
\text { Rg.KerjaStaf, Rg.Tamu } \\
\text { dan Toilet Pria dan } \\
\text { Wanita. }\end{array}$ \\
\hline 2 & $\begin{array}{l}\text { Unit Pengelola; } \\
\text { Operasional }\end{array}$ & $\begin{array}{l}\text { Rg.Kepala Bagian, } \\
\text { Rg.Wakil Kepala, Rg. } \\
\text { Sekertaris, Rg. Kerja } \\
\text { Operasional, Rg. } \\
\text { Pengatur Perjalanan } \\
\text { Kereta Api (PPKA), }\end{array}$ \\
\hline
\end{tabular}

\begin{tabular}{|c|c|c|}
\hline & & $\begin{array}{l}\text { Pengawas Peron } \\
\text { (RAP), Ruang } \\
\text { Kondektur/Kondektris, } \\
\text { Toilet pria dan Wanita. }\end{array}$ \\
\hline & $\begin{array}{l}\text { Unit Pengelola; } \\
\text { Perbendaharaan } \\
\text { dan Administrasi }\end{array}$ & $\begin{array}{l}\text { Rg. Kepala Bagian, Rg. } \\
\text { Wakil Kepala, Rg. } \\
\text { Sekertaris, Rg. } \\
\text { StafAdministrasi, Rg. } \\
\text { Tamu, Rg. Rapat, } \\
\text { Kantor Tata Usaha, Rg. } \\
\text { Perbendaharaan, } \\
\text { Kantor Keuangan, Rg. } \\
\text { Arsip dan Toilet Pria } \\
\text { dan Wanita. }\end{array}$ \\
\hline 4 & $\begin{array}{l}\text { Fasilitas } \\
\text { Pelayanan Stasiun }\end{array}$ & $\begin{array}{l}\text { LoketTiket, Hall, } \\
\text { Kantor Tiket, Check-in } \\
\text { Room, } \\
\text { BoardingRoom,Rg. } \\
\text { Tunggu Kelas Bisnis, } \\
\text { Rg. Tunggu Kelas } \\
\text { Ekonomi, Rg. Tunggu } \\
\text { Kelas VIP, Cafe, Fast } \\
\text { Food, Informasi, } \\
\text { Finding Lost/ Bagasi, } \\
\text { RuangKeamanan, } \\
\text { Ekspedisi, Peron, P3K, } \\
\text { Toilet Pria dan Wanita. }\end{array}$ \\
\hline 5 & $\begin{array}{l}\text { Fasilitas } \\
\text { Penunjang }\end{array}$ & $\begin{array}{l}\text { Cafetaria, Food Court, } \\
\text { Retail, ATM Center, } \\
\text { Musholla, Klinik, } \\
\text { RuangLaktasi dan } \\
\text { IbuHamil, Biro } \\
\text { Perjalanan, } \\
\text { Minimarket, Cafe, } \\
\text { Disable Pessengers } \\
\text { Room. dan } \\
\text { Rg.Peralatan. }\end{array}$ \\
\hline \multirow[t]{2}{*}{6} & $\begin{array}{l}\text { Fasilitas } \\
\text { Pelengkap }\end{array}$ & $\begin{array}{l}\text { Halte Pete-Pete, Halte } \\
\text { Bus, Plaza, Drop Off, } \\
\text { Parkir }\end{array}$ \\
\hline & FasilitasServis & $\begin{array}{l}\text { Rg. Istirahat, Rg. } \\
\text { Cleaning Service, } \\
\text { Janitor, Rg.Loker, Rg. } \\
\text { Trafo dan Panel } \\
\text { Control, Rg. AHU, Rg. } \\
\text { Genset, RuangPompa, } \\
\text { Toilet Pria dan Wanita. }\end{array}$ \\
\hline
\end{tabular}

Tabel.2 Rekapitulasi Besaran Ruang 


\begin{tabular}{|c|c|c|c|}
\hline No & $\begin{array}{l}\text { Kebutuhan } \\
\text { Ruang }\end{array}$ & Luasan (m2) & Keterangan \\
\hline 1 & $\begin{array}{l}\text { Fasilitas } \\
\text { Pengelola }\end{array}$ & 633,3925 & \multirow[t]{4}{*}{ Bangunan } \\
\hline 2 & $\begin{array}{l}\text { Fasilitas } \\
\text { Pelayanan }\end{array}$ & $11927,812+2520,9$ & \\
\hline 3 & $\begin{array}{l}\text { Fasilitas } \\
\text { Penunjang }\end{array}$ & 1128,27 & \\
\hline 4 & $\begin{array}{l}\text { Fasilitas } \\
\text { Servis }\end{array}$ & 506,194 & \\
\hline \multicolumn{3}{|c|}{ Total Luasan } & 16716,5685 \\
\hline \multirow[t]{2}{*}{5} & $\begin{array}{l}\text { Lahan } \\
\text { Terbuka }\end{array}$ & $\begin{array}{r}\text { (Tot. besaran } \\
\text { bangunan x } 40) \text { : } \\
60 \\
\end{array}$ & \multirow[t]{3}{*}{ Ruang Luar } \\
\hline & & 11144,379 & \\
\hline 6 & $\begin{array}{l}\text { Fasilitas } \\
\text { Pelengkap }\end{array}$ & 6552,91 & \\
\hline \multicolumn{3}{|c|}{ Total Luasan } & 17697,289 \\
\hline \multicolumn{3}{|c|}{ Flow Site 30\% } & 10324,15725 \\
\hline \multicolumn{3}{|c|}{$\begin{array}{l}\text { Total Luasan Bangunan dan Ruang } \\
\text { Luar }\end{array}$} & \multirow[t]{2}{*}{44738,014} \\
\hline \multirow{2}{*}{\multicolumn{3}{|c|}{$\begin{array}{l}\text { (Tot. Luas Bangunan + Tot. Ruang } \\
\text { Luar + Flow Site }\end{array}$}} & \\
\hline & & & $\begin{array}{r} \pm 4,5 \\
\text { Hektar }\end{array}$ \\
\hline
\end{tabular}

c. Zoning Ruang \& Sirkulasi Tapak

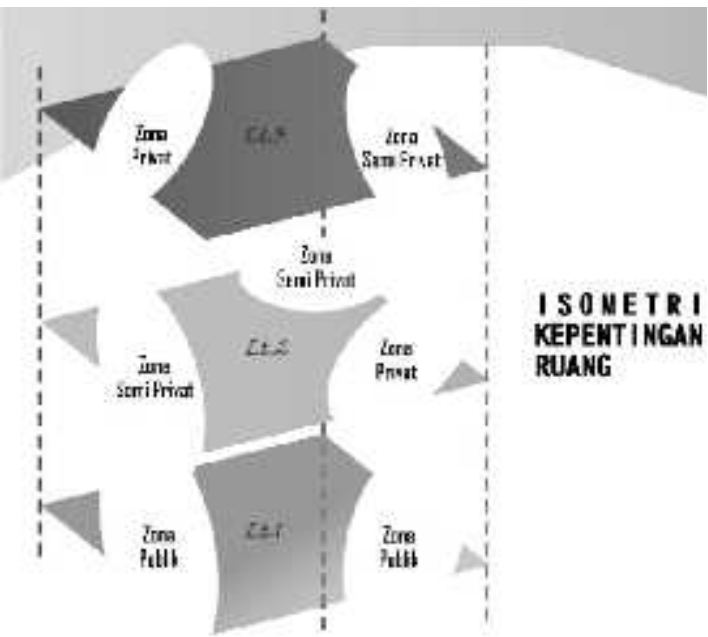

Gambar 7. Isometri Ruang

Fungsi kegiatan pada tapak dikelompokkan ke dalam beberapa zona, yaitu: zona public (umum) yang merupakan daerah yang dapat dicapai dengan bebas oleh publik, dan letaknya harus mudah dicapai dari pintu utama, zona semi publik (merupakan peralihan antara zona publik dan privat yang menuntut suasana yang tenang dan nyaman, zonaprivat (merupakan daerah yang tidak bebas dijangkau oleh orang (publik) atau daerah tertutup).

Alat sirkulasi bangunan stasiun diantaranya :

- Sirkulasi vertikal yang terdiri atas tangga, eskalator dan ramp.
- Sirkulasi horizontal yakni berupa koridor dan lantai yang langsung mengarah pada unit tiap lantai dengan bentuk jalur linear.

Pada bangunan stasiun ini digunakan pola tata massa tunggal.

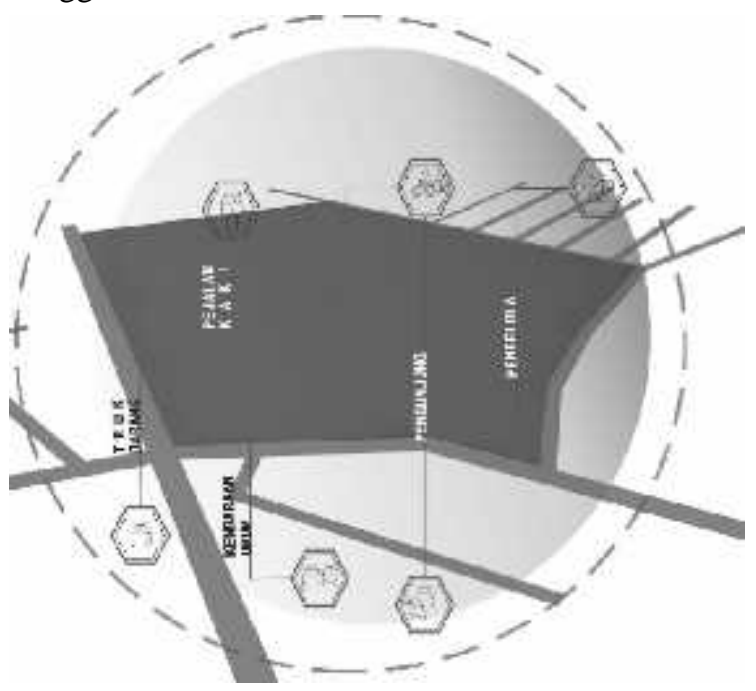

Gambar 8. Pola Tata Massa

\section{d. Bentuk Bangunan}

Ekspresi bentuk bangunan Stasiun Kereta Api ini menunjukkan perwujudan dari konsep utopia dengan pengungkapan citra diantaranya :

- Pemilihan dan modifikasi bentuk dasar bangunan yang kreatif sebagai gabungan bentuk dasar yang fleksibilitas dari segi ruang, struktur, efisiensi ruang, dan sirkulasi tapak dan bangunan.

- Balance bangunan dan proporsinya dengan pertimbangan dapat menciptakan deretan elemen visual yang mencerminkan dinamisasi citra bangunan.

- Aksentuasi dapat menghindarkan pengunjung dari kejenuhan bentuk.

- Skala bangunan yakni dengan meninjau skala manusia sehingga memunculkan kesan monumental pada bangunan sesuai konsep utopia yang dipilih.

- Tekstur dan komposisi material yang mampu menonjolkan dinamisnya bangunan.

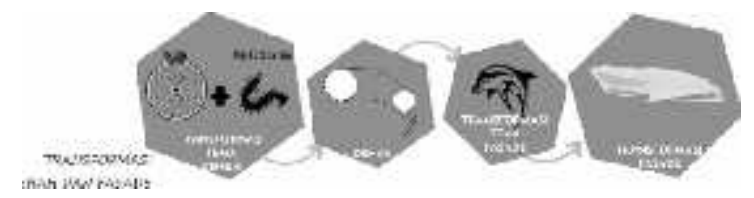

Gambar 9. Bentuk Bangunan

Pada area ruang luar terdapat akses untuk disable passangers seperti terdapatnya ramp pada jalur sirkulasi bangunan, dengan elemen pembentuk ruang luar yakni hard material dan soft material. 


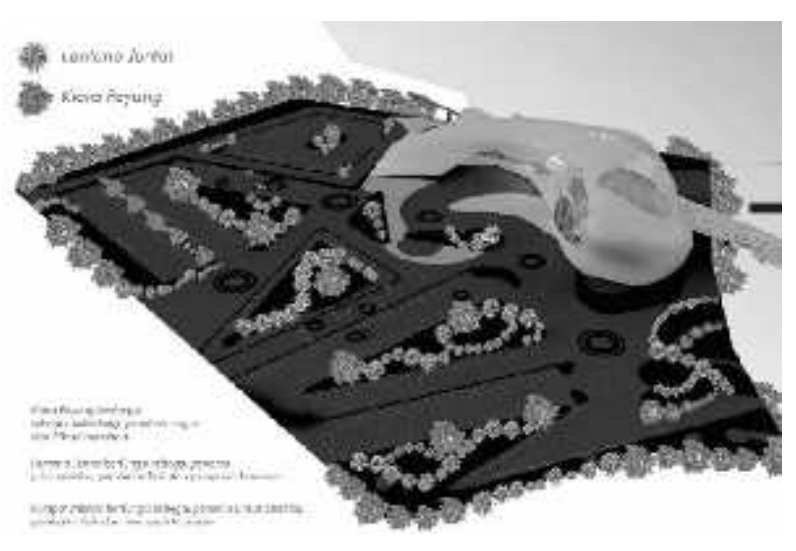

Gambar 10. Ruang Luar

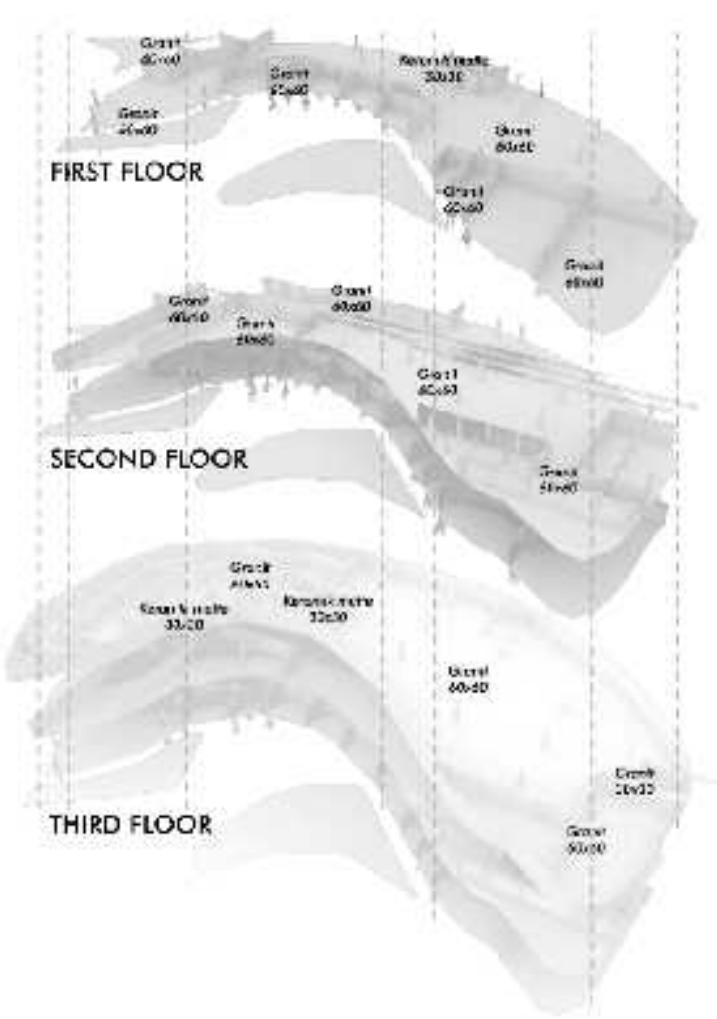

Gambar 11. Ruang Dalam

\section{e. Struktur dan Utilitas Bangunan}

Berikut sistem struktur yang digunakan :

- Upper struktur dengan system struktur rangka ruang yang dikombinasikan dengan struktur beton dengan serat kaca dicampur beton dan fiberglass dicampur polyester sebagai pelapis fasade bangunan.

- Sub struktur yang berfungsi sebagai penopang bangunan yang menyalurkan beban bangunan terhadap tanah sehingga dibutuhkan ketelitian karena struktur yang digunakan harus sesuai dengan jeni stanah, yang dipilih untuk bangunan Stasiun Kereta Api adalah pondasi tiang pancang yakni bentuk pondasi dalam yang dibangun di dalam permukaan tanah dengan kedalaman tertentu. Sistem kerja pondasi ini hamper sama dengan Pondasi Bore Pile yaitu meneruskan beban stuktur bangunan di atas ketanah dasar dibawahnya sampai kedalaman tanah yang dianggap kuat (memiliki daya dukung yang cukup).

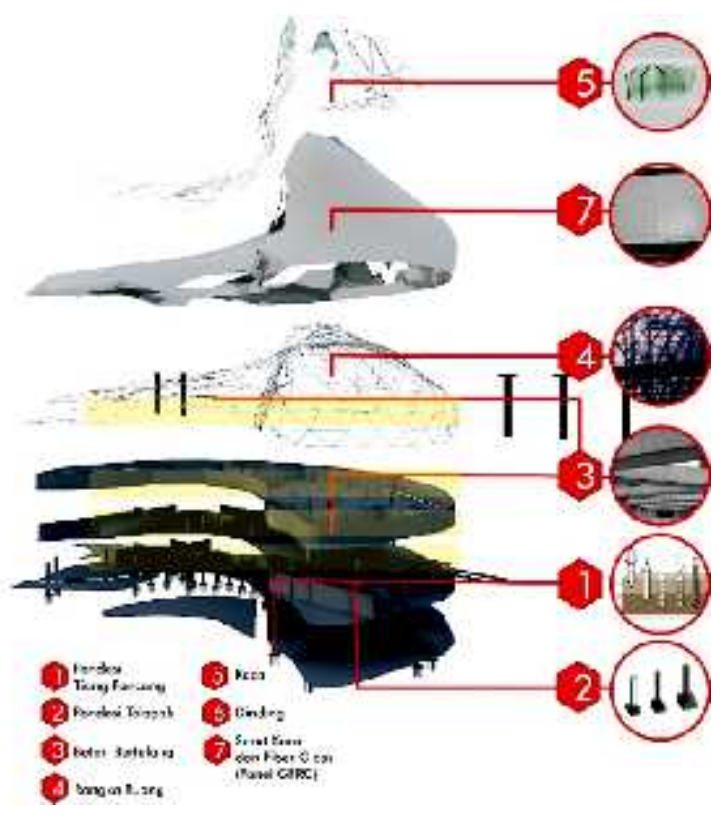

Gambar 12. Struktur \& Material

Berikut sistem utilitas pada Stasiun Kereta Api :

- SistemDistribusi Air Bersih

Distribusi air untuk kebutuhan sehari-hari menggunakan air PDAM sebagai pemenuhan kebutuhan primer bangunan dengan penanggulangan kemungkinan terjadinya kebakaran sedangkan untuk kebutuhan servis/ pelayanan dan cadangan menggunakan air sumurbor/ deep well.

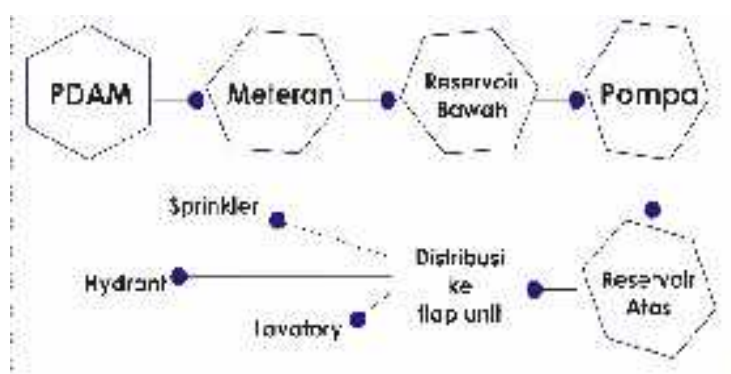

Gambar 13. Sistem Distribusi Air Bersih

- Sistem Jaringan Air Kotor

Air kotor berasal dari water closet, lavatory, dan floordrain dimana pembuangan airnya digabungkan di satutempat. Setiap plumbing fixtures yang terpasang dilengkapi dengan $U$ trap dan pada awal saluran dipasang CleanOut(CO) untuk maintenance. Air buangan dari pipa-pipa tersebut disalurkan ke pipa induk menuju pengolahan terakhir. Material penampung terbuat dari konstruksi beton yang terbagi dari beberapa bagian menjadikan tahapan proses untuk mendapatkan 
kualitas air buangan yang disyaratkan. Bekas air dari kamar mandi dan westafel melalui bak control terlebih dahulu sebelum keriol kota, sedangkan air buangan dari septictank dan dapur harus melalui bak pengolahan lalu keriol kota.

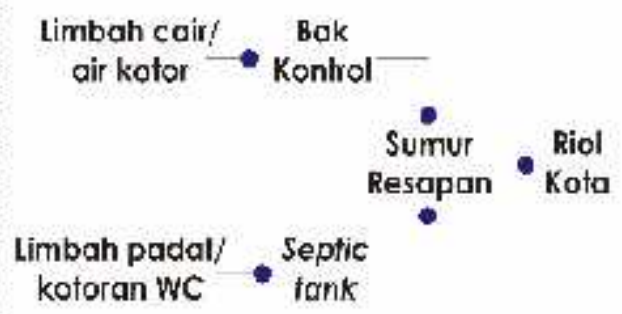

Gambar 14. Sistem Distribusi Air Kotor

- Sistem Jaringan Listrik

Sumber daya listrik berasal dari PLN dan sebagai sumber daya listrik cadangan, disediakan generator set yang secara otomatis bekerja apabila pasokan listrik utama mati. Perbaikan system mekanika lelektrikal (ME) dapat dengan menggunakan system Tranking dan juga system catwalk. Berikut hal-hal analisa jaringan listrik :

1) Sumber listrik berasal dari pasokan PLN

2) Tersedia generator (genset)

3) Terdapat ruang bagi saluran listrik dalam bangunan agar mudah dilakukan maintenance dan diletakkan dalam keadaan tersembunyi/ system tertutup.

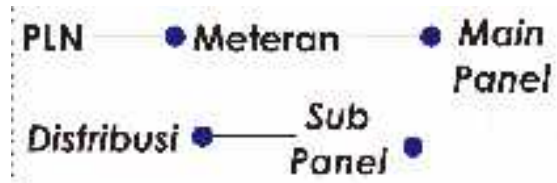

Gambar 15. Sistem Jaringan Listrik

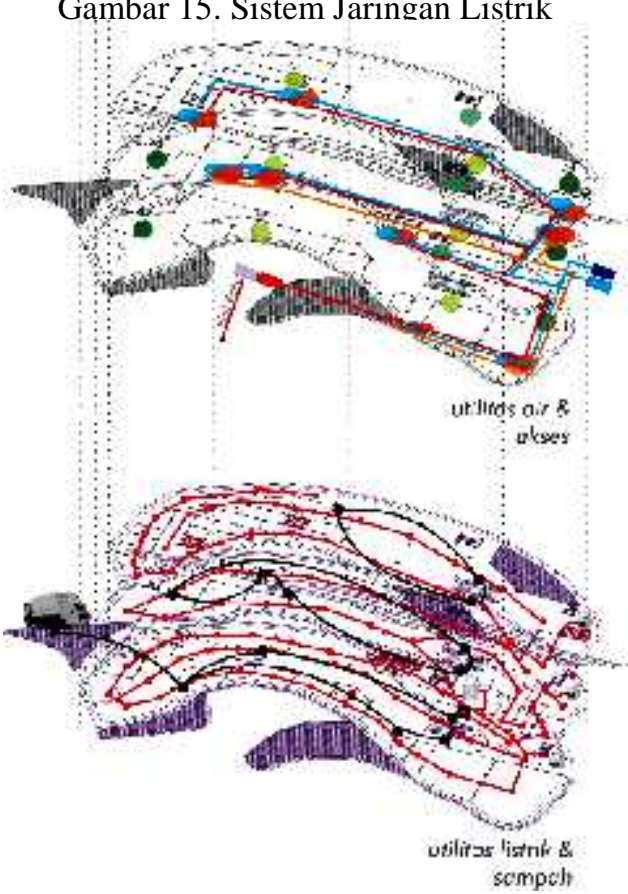

Gambar 16. Utilitas Bangunan

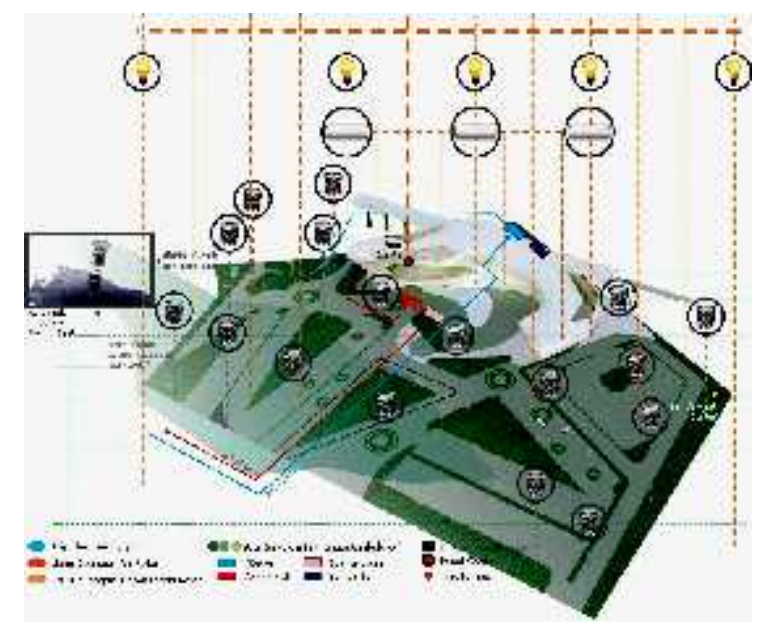

Gambar 17. Sistem Utilitas Tapak

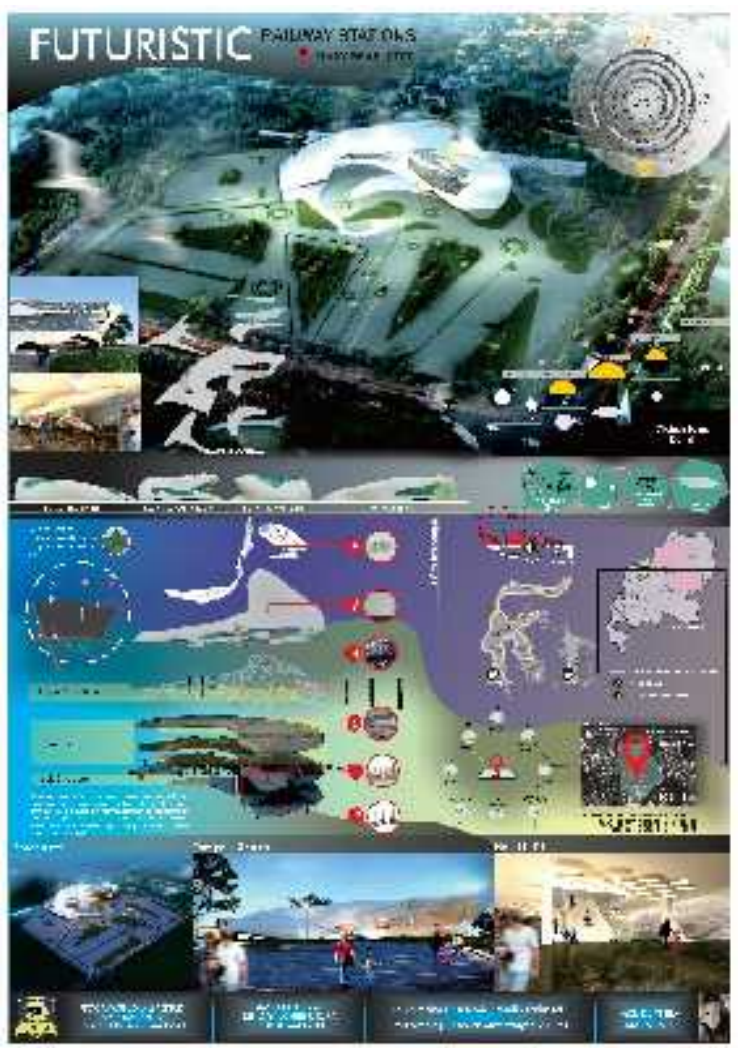

Gambar 18. Poster Rancangan Stasiun Kereta Api

\section{PENUTUP}

\section{Kesimpulan}

Maka dapat disimpulkan hal-hal sebagaiberikut:

LokasiStasiun diKecamatan Tallo unggul karena:

a. Kecamatan Tallo merupakan lintasan pertama dari jalur kereta api koridor MakassarParepare.

b. Lokasi yang strategis merupakan kawasan Makassar New Port dan mudah diakses masyarakat, tersedia jaringan utilitas dan luasan lahan memenuhi sehingga mendukung penerapan konsep utopia.

c. Eksisting tapak tidak berkontur (relatif datar) sehingga dapat diberikan kontur buatan. 
d. Konsep utopia yang menuntut bentuk ekstrim pada bangunan menjadikan adanya modifikasi bentuk dasar sehingga dihasilkan bentuk fisik yang futuristik.

e. Perbandingan antara nilai koefisien dasar bangunan dan lahan terbuka yang digunakan adalah 60 : 40 pada tapak seluas $\pm 4,8$ hektar dengan nilai rekapitulasi kebutuhan ruang $\pm 4,5$ hektar sehingga $\pm 0,3$ hektarnya lahan pengembangan atau perluasan.

\section{REFERENSI}

Apung, H.T. (2013): Planetarium Astronomi di Makassar Pendekatan Arsitektur Futuristik, Skripsi Tugas Akhir Program Studi Arsitektur Universitas Hasanuddin, 35-45.

Azizi, A.Y. (2015): Tugas Stasiun, Emplasemen dan Pensinyalan,http:// dokumen.tips/documents/tugasstasiun-emplasemen-dan-persinyalan.html,

Download (diturunkan/diunduh) pada 12 November 2016.

Claeys, G. (2010): The Cambridge Companion To UTOPIAN LITERATURE, Cambridge University Press, 6.

Handinoto, H. (1999): Perletakan Stasiun Kereta Api Dalam Tata Ruang Kota-Kota Di Jawa (Khususnya Jawa Timur) Pada Masa Kolonial, Jurusan Teknik Arsitektur Fakultas Teknik Sipil dan Perencanaan Universitas Kristen Petra, 48-56.

Krisnawan, G. (2013): Utopia, The Sake of The Future, https://www.scribd.com/document/322091331/Ars itektur-Utopia, Download (diturunkan/ diunduh) pada 12 November 2016.

Levitas, R. (2010): The Concept of Utopia, Peter LangDie Deutsche Nationalbibliothek, 9-20.

Neufert, Ernst.(1996). Data Arsitek (Jilid 1 - Edisi ke33), Terjemahan oleh Dr.Ing. SunartoTjahjadi, 712.

Neufert, Ernst. (1994). Data Arsitek (Jilid 2 - Edisi ke2), Terjemahan oleh SjamsuAmril, 14-15.

Rosinta, F. (2015): Undang-UndangTransportasi II StasiunKeretaApi, https://www.academia. edu/9468988/STASIUN_KERETA_API,

Download (diturunkan/diunduh) pada 12 November 2016.

Sugara, H. (2010): Redesain Stasiun Kereta Api Wonogiri Sebagai Sarana Pariwisata, Program Perencanaan dan PerancanganArsitektur (P3A), $1-14$.

Titasari, S. (2005): Pengembangan Stasiun Kereta Api Jakarta Kota, Landasan Program Perencanaan dan Perancangan Arsitektur, 1-6.

Tyas,I.P. (2013). Jenis Konsep Arsitektur, https://ikapurwaningtyas.wordpress.com/2016/01/ 23/5-jenis-konsep-arsitektur/,Download diturunkan /diunduh) pada 19 November 2016.

Witsqha, N. (2016): Arsitektur Utopian, https://ikapurwaningtyas.wordpress.com
2016/01/23/arsitektur-utopian/,Download (diturunkan /diunduh) pada 6 Desember 2016. 